Mens

Revue d'histoire intellectuelle et culturelle

\title{
Présentation
}

\section{Anne Caumartin}

Volume 16, numéro 1, automne 2015

URI : https://id.erudit.org/iderudit/1038981ar

DOI : https://doi.org/10.7202/1038981ar

Aller au sommaire du numéro

Éditeur(s)

Centre de recherche en civilisation canadienne-française

ISSN

1492-8647 (imprimé)

1927-9299 (numérique)

Découvrir la revue

Citer ce document

Caumartin, A. (2015). Présentation. Mens, 16(1), 5-6.

https://doi.org/10.7202/1038981ar

Ce document est protégé par la loi sur le droit d'auteur. L'utilisation des services d'Érudit (y compris la reproduction) est assujettie à sa politique d'utilisation que vous pouvez consulter en ligne.

https://apropos.erudit.org/fr/usagers/politique-dutilisation/
Cet article est diffusé et préservé par Érudit.

Érudit est un consortium interuniversitaire sans but lucratif composé de l’Université de Montréal, l'Université Laval et l'Université du Québec à Montréal. Il a pour mission la promotion et la valorisation de la recherche. https://www.erudit.org/fr/ 


\section{Présentation}

Cette livraison de Mens est consacrée à la vie musicale à Montréal au début du $\mathrm{Xx}^{\mathrm{e}}$ siècle. Comme l'indique Sandria P. Bouliane dans l'introduction au dossier, la vie musicale tant amateur que populaire a offert une façon d'habiter la ville que l'on mesure encore difficilement aujourd'hui. Sur le plan culturel, Montréal s'est située par rapport aux autres métropoles et a exprimé de façon originale son américanité. En montrant la diversité de la vie culturelle montréalaise et la pluralité de ses influences et des lieux investis, ce dossier apporte une contribution originale à l'histoire de la musique au Québec.

Peggy Roquigny présente les pratiques de la danse sociale à Montréal pendant l'entre-deux-guerres. Le jazz et les danses alors en vogue popularisent cette forme de divertissement et suscitent la création de divers lieux, qu'ils soient réservés aux initiés ou ouverts à un large public. Les restaurants dansants, les cabarets, les salles de danse permettent de réserver un temps à la musique, en marge de la routine quotidienne, et participent aussi à la transformation identitaire de Montréal en façonnant les modalités de la rencontre des classes sociales et des divers groupes ethniques et linguistiques. La danse, par les lieux et les événements qu'elle crée, constitue non seulement une voie d'intégration sociale, mais est aussi l'occasion de réévaluer l'idée de convenance : en passant d'un loisir privé à un divertissement public, la danse permet, entre autres, aux femmes de redéfinir leur posture par rapport aux discours normatifs.

Luc Bellemare, quant à lui, examine les caractéristiques des cabarets. En suivant l'évolution d'un cabaret du Quartier latin à Montréal au tournant des années 1930, il est possible d'évaluer la portée - et la longévité - des influences parisienne et new-yorkaise sur la vie musicale montréalaise alors que ces influences se concilient avec l'identité canadienne. L'apparition du Matou botté dans le contexte des années 1920 amène les propriétaires à présenter d'abord des danses et des sketches offerts à Montmartre, à Paris; mais la 
dualité culturelle de Montréal requiert des spectacles qui la reflètent. Bien vite, on exploitera la nouveauté qu'est le jazz, en présentant des spectacles qui se veulent davantage d'influence américaine. Malgré cette capacité d'adaptation, le succès est mitigé. Selon Bellemare, plusieurs facteurs expliquent ce résultat, comme le contexte culturel (la concurrence du cinéma, l’orientation idéologique de la littérature) et les avancées techniques (l'amélioration de la qualité des supports médiatiques) qui influencent les modes de consommation de la musique.

Enfin, Catherine Lefrançois examine comment les pratiques de la chanson country-western au Québec ont pu se transformer au cours des années 1940. En revenant sur le parcours de figures importantes du genre - le soldat Lebrun, Paul Brunelle, Willie Lamothe, Marcel Martel-, Lefrançois explique le processus de professionnalisation de ces amateurs par le rôle de la radio et les rapports que ces chanteurs entretenaient avec le public. Grâce à la faveur populaire, qui se manifeste surtout en région, la chanson country-western gagne en crédibilité, et ses interprètes délaissent les reprises pour créer un répertoire canadien-français original qui investira les studios d'enregistrement montréalais.

Sur une plus triste note, le comité de rédaction de Mens tient à souligner le décès du père Benoît Lacroix, figure marquante de la vie intellectuelle et spirituelle au Québec. Michel Biron, professeur au Département de langue et littérature françaises de l'Université McGill, offre ici un hommage au lecteur attentif et attentionné du poète Hector de Saint-Denys Garneau et à son travail d'édition critique de l'œuvre garnélienne, aujourd'hui indispensable. Mens reconnaît, à la suite de Michel Biron, l'intellectuel qui a su, en toute amitié, « donner à lire » Saint-Denys Garneau, rendre sa poésie vivante et montrer, de ce fait, son pouvoir d'accompagnement.

Anne Caumartin Pour l'équipe de Mens 